Revista Brasileira de Cartografia

ISSN 1808-0936 | https://doi.org/10.14393/revbrascartogr

Sociedade Brasileira de Cartografia, Geodésia, Fotogrametria e Sensoriamento Remoto

\title{
Avaliação da Incerteza de Dados Batimétricos Coletados por meio de Plataformas Autônomas não Tripuladas
}

\section{Uncertainty Assessment of Bathymetric Data Collected Through Unmanned Autonomous Platforms}

Italo Oliveira Ferreira ${ }^{1}$, Laura Coelho de Andrade ${ }^{2}$, Larissa Messias de Souza ${ }^{3}$, Arthur Amaral e Silva ${ }^{4}$ e Felipe Catão Mesquita Santos ${ }^{5}$

1 Universidade Federal de Viçosa, Departamento de Engenharia Civil, Viçosa, Brasil. italo.ferreira@ ufv.br. ORCID: https://orcid.org/0000-0002-4243-8225

2 Universidade Federal de Viçosa, Departamento de Engenharia Civil, Viçosa, Brasil. laura.andrade@ufv.br. ORCID: https://orcid.org/0000-0003-3693-2208

3 Universidade Federal de Viçosa, Departamento de Engenharia Civil, Viçosa, Brasil. larissa.messias@ufv.br. ORCID: https://orcid.org/0000-0002-7767-1131

4 Universidade Federal de Viçosa, Departamento de Engenharia Civil, Viçosa, Brasil. arthur.amaral@ufv.br ORCID: https://orcid.org/0000-0001-5548-459X

5 Universidade Federal de Viçosa, Departamento de Engenharia Civil, Viçosa, Brasil. felipe.mesquita@ufv.br ORCID: https://orcid.org/0000-0002-9376-766X

Resumo: A hidrografia consiste em uma ciência correlacionada a geografia física, que estuda todos os tipos e variações de corpos aquáticos. Para uma descrição coerente do fundo submerso, comumente utilizam-se embarcações tripuladas equipadas com sistemas de sondagem para a realização de um levantamento hidrográfico. Todavia, a dificuldade de acesso às áreas remotas, ou até mesmo a insegurança existente pelo fato de a localidade oferecer risco aos tripulantes fez com que o uso de veículos autônomos não tripulados se tornasse cada vez mais comum. Nessa conjuntura, sabe-se que os levantamentos hidrográficos conduzidos por essas plataformas, assim como qualquer outro tipo de levantamento, conterão incertezas que irão afetar diretamente os dados batimétricos. Diante disso, este artigo objetiva apresentar uma metodologia para avaliação teórica da Incerteza Propagada Total (IPT) de sistema de sondagem batimétrica embarcados em ASV's (Autonomous Surface Vessel), bem como validar o modelo teórico por meio da confrontação dos resultados obtidos com as incertezas amostrais adquiridas em um levantamento batimétrico realizado na Laguna da Jansen em São Luís-MA. Os resultados evidenciaram que o modelo de incertezas teórico é coerente com as incertezas amostrais obtidas.

Palavras-chave: Hidrografia. Batimetria. Incerteza amostral. Propagação de incertezas.

Abstract: Hydrography consists in a science related to physical geography, which studies all types and variations of aquatic bodies. For a coherent submerged bottom description, manned vessels equipped with sounding systems are commonly used to carry out a hydrographic survey. However, the difficulty of access to remote areas or even guarantees the fact that location poses a risk to crew members made the use of unmanned autonomous vehicles become increasingly common. At this juncture, it is known that hydrographic surveys conducted by these platforms, as well as any other type of survey, contain uncertainties that directly affects bathymetric data. Thus, this article aims to present a methodology for the theoretical assessment of Total Propagated Uncertainty (TPU) in ASV (Autonomous Surface Vessel), as well as to compare the results with sample uncertainty acquired in a bathymetric survey, at Jansen's Lagoon in São Luís-MA, to finally carry out the uncertainty model validation. The results showed that the theoretical uncertainty model is coherent with the sample uncertainties obtained.

Keywords: Hydrography. Bathymetry. Sample uncertainties. Propagation of uncertainties. 


\section{INTRODUÇÃO}

$\mathrm{Na}$ atualidade, a realização de levantamentos hidrográficos (LH) concentra-se no uso de ecobatímetros para medição de profundidade, sensores inerciais para controle da atitude da embarcação e receptores GNSS (Global Navigation Satellite System) diferenciais para determinação da posição, além de perfiladores de velocidade do som. Assim, a determinação da profundidade e posição baseiam-se na integração de diversas medições individuais além daquelas efetivamente realizadas pelos sonares. Todas essas medições são realizadas com um certo grau de incerteza, sendo, portanto, propagadas para o produto final (Modelo Batimétrico) (HARE, 1995; HARE et al., 2011; FERREIRA et al., 2016a).

A execução desses levantamentos supracitados, bem como a obtenção de dados precisos é substancialmente mais complexo e moroso do que a coleta de dados topográficos ou geodésicos (BYRNES et al., 2002; CHURCH, 2020). Sabe-se que na Topografia a superfície a ser mapeada é visível, sendo assim, pontos de mudança de declividade, acidentes geográficos, dentre outros, podem ser facilmente localizados e levantados. Também é possível materializar pontos de apoio e efetuar medições repetidas, para um posterior ajustamento de observações (FERREIRA et al., 2017). Tais procedimentos e artifícios teóricos estão indisponíveis para os hidrógrafos. Ao contrário do levantamento terrestre, a Hidrografia possui poucos indicadores de controle de qualidade que fornecem uma medida de incerteza resultante (incerteza amostral) e além disso, a superfície mapeada não é visível, o que dificulta até mesmo a identificação de erros grosseiros.

Segundo Ferreira et al. (2019a), diversas fontes de incertezas são observadas nos levantamentos hidrográficos, como por exemplo, aquelas associadas a estimativa da velocidade de propagação do som, ao estabelecimento do datum vertical, definição do sistema de coordenadas da embarcação e aos movimentos da dinâmicos durante a coleta de dados.

Uma vez que um dos objetivos principais de um LH consiste em produzir informações que suportam a segurança na navegação marítima e fluvial, o controle de qualidade do dado coletado e dos produtos finais tornaram-se cada vez mais importantes. Avaliar a qualidade, bem como detectar, analisar e eliminar dados discrepantes, tornaram-se tarefas indispensáveis. Soma-se a isso, o fato de a destinação do produto final ser altamente dependente da sua qualidade (LUCIEER et al., 2016; KREITMAIR et al., 2019). A Publicação Especial S-44, na sua 6 a edição que deverá entrar em vigor no ano de 2021, já prevê uma nova ordem de levantamento hidrográfico, chamada de Ordem Exclusiva, que restringe ainda mais os requisitos mínimos que deverão ser alcançadas nas coletas de dados batimétricos (IHO, 2020).

Basicamente, existem duas formas de se estimar a incerteza dos dados batimétricos. A primeira, muito comum nas tarefas que antecedem os trabalhos de campo, consiste em avaliar e modelar todas as fontes de incertezas associadas ao sistema de sondagem batimétrica e, por meio da lei de propagação de incertezas, estimar a Incerteza Vertical Total (IVT) e a Incerteza Horizontal Total (IHT). A soma geométrica destes parâmetros fornece a Incerteza Propagada Total (IPT) (PEREIRA, 2016; FERNANDES et al., 2018; EREN et al., 2019).

Apesar de ser uma metodologia comumente empregada, deve-se atentar que um modelo teórico de incertezas apenas fornece uma estimativa da qualidade do levantamento baseada nos possíveis desvios não correlacionados do sistema de sondagem (HARE, 1995; IHO, 2005; LINZ, 2010), sendo preferível que a incerteza seja calculada com base em observações redundantes, o que origina a segunda forma de estimativa de incertezas.

Alternativamente, pode-se, assim como nas ciências geodésicas, estimar a incerteza por meio de discrepâncias advindas do levantamento de pontos homólogos. Porém, como discutido, nas ciências hidrográficas a obtenção de redundância é algo impraticável. Mesmo que a embarcação percorra a mesma linha e à mesma velocidade, o espaçamento entre feixes e o intervalo entre transmissões sucessivas do feixe sonoro tornam essa redundância praticamente impossível (CALDER; MAYER, 2003; CLARKE, 2014).

Diante dessa dificuldade, no âmbito da hidrografia realizam-se linhas de verificação planejadas de forma aproximadamente perpendicular às linhas regulares de sondagem. No cruzamento entre as linhas, aplicam-se algoritmos com vistas a definir "pontos homólogos", que após tratamento estatístico adequado fornecem a incerteza vertical amostral das profundidades coletadas (SPECHT; SPECHT, 2018; HOY; WHITE, 2020). 
No caso da incerteza horizontal amostral, ainda não se observa na literatura metodologias viáveis. Entretanto, na prática hidrográfica, instala-se o receptor GNSS diferencial utilizado no sistema de sondagem sobre um ponto de coordenadas conhecidas em terra (marco geodésico) e assim realiza-se uma comparação entre as diversas coordenadas registradas pelo receptor no modo cinemático e aquelas já conhecidas, para $a$ posteriori, aplicar estatísticas, como o RMS (Root Mean Square) ou Desvio padrão da média, com o propósito de estimar a incerteza horizontal amostral (SENIOR, 2012).

Sabe-se que os dados hidrográficos, em especial a batimetria, são obtidos por meio de um conjunto de instrumentos instalados em plataformas de levantamentos, que podem ser submergíveis, como os AUVs (Autonomous Underwater Vehicle), de superfície, como embarcações e navios, e também plataformas aéreas (JI; LIU, 2015; FERREIRA et al., 2016b; MOUSAZADEH et al., 2017; FERNÁNDEZ-MONTBLANC et al., 2018; FERNANDES et al., 2018). Em todos os casos, estas plataformas podem ser tripuladas ou não. Pode-se embarcar uma enorme variedade de instrumentos: sensores inerciais, receptores GNSS, perfiladores de velocidade do som, sonares de varredura lateral, perfiladores de subfundo e ecobatímetros. No contexto das plataformas aéreas, a batimetria é obtida utilizando-se desde imagens orbitais ou aerofotogramétricas até sistemas LiDAR (Light Detection And Ranging) (GAO, 2009; CHENG et al., 2015; BANDINI et al., 2018).

Nos últimos tempos, as plataformas de superfície não tripuladas, denominadas frequentemente de ASV (Autonomous Surface Vessel), sofreram um grande avanço tecnológico, tendo seu uso aumentado eminentemente. Diversos autores desenvolveram pesquisas aplicando estes tipos de plataformas, especialmente como alternativa ao uso de embarcações tripuladas (MANLEY, 2008; ZHAO et al., 2011; GIORDANO et al., 2015).

Tais plataformas de superfície não tripuladas possuem, basicamente, as mesmas fontes de incertezas encontradas nos levantamentos conduzidos por meio de plataformas tripuladas. Sabe-se que essas fontes de incertezas, bem como o modelo de incertezas de sistemas de sondagem são amplamente conhecidos no meio hidrográfico e podem ser consultados, por exemplo, em Hare (1995); IHO (2005, 2008, 2020) e Ferreira et al. (2016a).

Todavia, não há relatos na literatura sobre a modelagem de incertezas para sistemas de sondagem batimétrica mobilizados em plataformas de superfície não tripuladas, tão pouco uma avaliação estatística da qualidade dos dados coletados. Assim, este trabalho objetiva de uma forma geral, apresentar um método para avaliação teórica da Incerteza Propagada Total de sistemas de sondagem batimétrica embarcados em ASV's.

Além disso, ao final, a metodologia foi aplicada no ASV EchoBoat, da fabricante americana SeaFloor, e os resultados de incerteza teórica (à priori) foram confrontados com as incertezas amostrais (à posteriori) obtidas em um levantamento batimétrico executado na Laguna da Jansen em São Luís - MA, visando a validação do modelo de incertezas. 


\section{EXPERIMENTOS E RESULTADOS}

O fluxograma a seguir resume as etapas empregadas neste trabalho (Figura 1).

Figura 1 - Fluxograma metodológico.

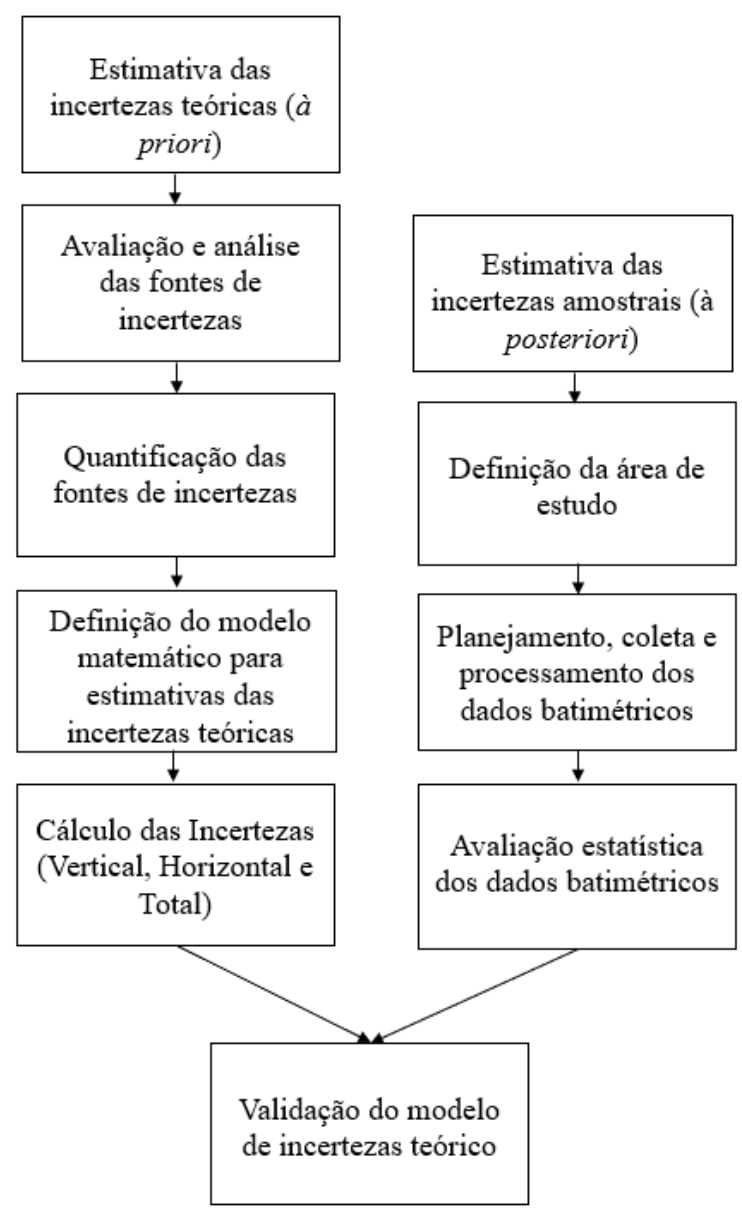

Fonte: Os autores (2021).

\subsection{Estimativa das incertezas teóricas}

Os ASV's consistem em embarcações não tripuladas que podem operar em modo autônomo, seguindo um planejamento pré-programado, ou ser controladas remotamente. Zhao et al. (2011) e Ferreira et al. (2017) apresentaram um panorama da utilização das plataformas não tripuladas na execução de pesquisas em ambientes submersos, descrevendo as tecnologias, principais incertezas envolvidas e as vantagens e desvantagens. Pesquisas relacionadas às plataformas não tripuladas também foram conduzidas por: Vaneck et al. (1996), Curcio et al. (2005), Manley (2008), Furfaro (2012), Giordano et al. (2015), dentre outros. Pode-se verificar que as fontes de incertezas presentes nos sistemas embarcados em plataformas não tripuladas são, quase sempre, os mesmos relacionados aos sistemas mobilizados em plataformas tripuladas.

Este estudo foi conduzido e direcionado para a estimativa das incertezas associadas ao sistema monofeixe montado a bordo do ASV, modelo Echoboat da empresa SeaFloor (Figura 2). De acordo com o manual do fabricante, o ASV é um veículo não tripulado desenvolvido para realização de pesquisa hidrográfica que possui funcionamento autônomo e com auxílio de controle remoto (com alcance de até $2 \mathrm{~km}$ ). O Echoboat atinge uma velocidade máxima em torno de $10 \mathrm{~km} / \mathrm{h}$ ( 5 nós), possui comprimento de $2 \mathrm{~m}$, largura de $0,8 \mathrm{~m}$, pesa cerca de $23 \mathrm{~kg}$ e um payload de até $29 \mathrm{~kg}$. Apresenta um motor composto por dois propulsores e uma bateria de duração média de 8 horas (SEAFLOOR SYSTEM, 2017). 
Figura 2 - Plataforma não tripulada, modelo EchoBoat ASV.

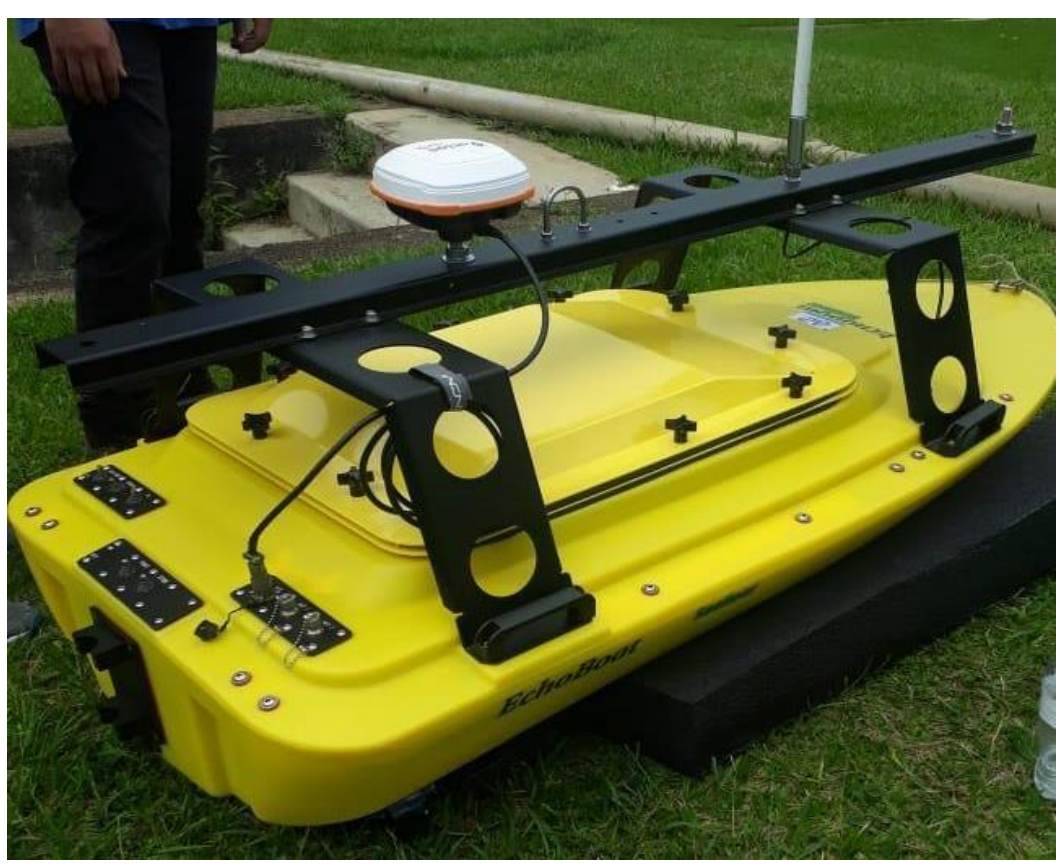

Fonte: Os autores (2021).

A embarcação não tripulada está equipada com os seguintes sensores:

a) ecobatímetro monofeixe Echotrac CV100 da Teledyne Marine;

b) transdutor SS510 da Airmar operando com uma frequência de $200 \mathrm{kHz}$;

c) receptor DGNSS (Differential Global Navigation Satellite System) Atlas Link;

d) IMU (Inertial Measurement Unit) DMS-05 da Teledyne Marine;

e) SVP (Sound Velocity Profiler) Digibar S da marca Teledyne Marine;

f) computador industrial, baterias e acessórios.

Diante disso, e seguindo as recomendações de Hare (1995), IHO (2005) e Ferreira et al. (2016a), nessa pesquisa foram consideradas as seguintes fontes de incertezas para um sistema de sondagem de feixe simples:

Fontes de Incertezas Horizontais:

a) incertezas do sistema de posicionamento;

b) incertezas associadas a sincronização do tempo / latência;

c) incertezas relacionadas às medições e compensações dos offsets lineares;

d) incertezas associadas aos movimentos de roll e pitch da embarcação.

Fontes de Incertezas Verticais (sistema monofeixe):

a) incertezas associadas à medição do draft estático e a sua variação durante o levantamento;

b) incertezas associadas ao draft dinâmico (Settlement e squat);

c) incerteza do sonar;

d) incertezas relacionadas aos movimentos da embarcação;

e) incertezas relacionadas a estimativa da velocidade do som;

f) incertezas relacionadas à maré e ao estabelecimento do Nível de Redução (Datum Vertical).

Estabelecido as fontes de incertezas, deve-se quantificá-las individualmente. Baseado em dados secundários, isto é, em catálogo dos instrumentos, consultas bibliográficas e experiências práticas, pôde-se 
estimar a maioria das fontes de incertezas verticais e horizontais.

Algumas delas, no entanto, não se propagam diretamente para a profundidade e/ou posição e, assim, necessitam ser modeladas matematicamente, dependendo nestes casos de outras informações tais como a velocidade da embarcação, a profundidade média e a largura do feixe do transdutor. Existem também aquelas que variam com a profundidade e que afetam ambas as componentes. As Tabelas 1 e 2 resumem as informações.

Tabela 1 - Incerteza Horizontal Total.

\begin{tabular}{l|c|c|c|c|c}
\hline \multicolumn{1}{c}{ INCERTEZA HORIZONTAL TOTAL (IHT) } & \multicolumn{3}{c}{ Profundidade (m) } \\
\hline \multicolumn{1}{c|}{ Fonte de incerteza } & $\begin{array}{c}\text { Parcela de incerteza } \\
\text { independente da } \\
\text { profundidade (m) }\end{array}$ & $\begin{array}{c}\text { Parcela de } \\
\text { incerteza } \\
\text { dependente da } \\
\text { profundidade (m) }\end{array}$ & $\mathbf{1 0}$ & $\mathbf{5 0}$ & $\mathbf{1 0 0}$ \\
\hline $\begin{array}{l}\text { Sistema de posicionamento } \\
\text { Latência do sistema de } \\
\text { posicionamento }\end{array}$ & 0,500 & & 0,500 & 0,500 & 0,500 \\
$\begin{array}{l}\text { Compensações e medições dos } \\
\text { offsets lineares }\end{array}$ & 0,100 & 0,100 & 0,100 & 0,100 \\
Incerteza em Roll e Pitch & 0,010 & 0,0009 & 0,010 & 0,010 & 0,010 \\
IHT $( \pm)$ & 0,51 & 0,0009 & 0,510 & 0,050 & 0,090 \\
\hline
\end{tabular}

Fonte: Os autores (2021).

Tabela 2 - Incerteza Vertical Total.

\begin{tabular}{|c|c|c|c|c|c|}
\hline \multicolumn{3}{|c|}{ INCERTEZA VERTICAL TOTAL (IVT) } & \multicolumn{3}{|c|}{ Profundidade (m) } \\
\hline Fonte de incerteza & $\begin{array}{c}\text { Parcela de incerteza } \\
\text { independente da } \\
\text { profundidade }(\mathbf{m})\end{array}$ & $\begin{array}{c}\text { Parcela de incerteza } \\
\text { dependente da } \\
\text { profundidade }(\mathbf{m})\end{array}$ & 10 & 50 & 100 \\
\hline Medição do draft estático & 0,020 & & 0,020 & 0,020 & 0,020 \\
\hline $\begin{array}{l}\text { Variação do draft estático } \\
\text { durante o levantamento }\end{array}$ & 0,010 & & 0,010 & 0,010 & 0,010 \\
\hline $\begin{array}{l}\text { Settlement e squat (draft } \\
\text { dinâmico) }\end{array}$ & 0,020 & & 0,020 & 0,020 & 0,020 \\
\hline Incerteza do sonar & 0,010 & 0,0010 & 0,010 & 0,050 & 0,100 \\
\hline Incerteza em roll e pitch & & 0,0013 & 0,010 & 0,070 & 0,130 \\
\hline Incerteza em heave & 0,100 & & 0,100 & 0,100 & 0,100 \\
\hline Medição da velocidade do som & & 0,0013 & 0,010 & 0,070 & 0,130 \\
\hline $\begin{array}{l}\text { Variação espacial da velocidade } \\
\text { do som }\end{array}$ & & 0,0006 & 0,010 & 0,030 & 0,060 \\
\hline $\begin{array}{l}\text { Variação temporal da velocidade } \\
\text { do som }\end{array}$ & & 0,0006 & 0,010 & 0,030 & 0,060 \\
\hline Incerteza dos dados de maré & 0,050 & & 0,050 & 0,050 & 0,050 \\
\hline Estabelecimento do NR & 0,050 & & 0,050 & 0,050 & 0,050 \\
\hline Incerteza cotidal $^{1}$ & 0,150 & & 0,150 & 0,150 & 0,150 \\
\hline $\operatorname{IVT}( \pm)$ & 0,200 & 0,0023 & 0,200 & 0,230 & 0,300 \\
\hline
\end{tabular}

Fonte: Os autores (2021).

É importante destacar que os valores apresentados nas Tabelas 1 e 2 não correspondem a magnitude das correções aplicadas ou que devam ser aplicadas. Consistem, em suma, na magnitude do resíduo após as correções apropriadas (para maré, draft, latência, etc.). Além disso, as incertezas apresentadas foram quantificadas ou normalizadas para um nível de confiança de $95 \%$.

No que concerne às fontes de incertezas horizontais, a incerteza relacionada ao sistema de posicionamento e a latência, foi definida com base em Mundy (2017) e Hemisphere (2018). Salienta-se que foi considerado um tempo de convergência de 5 minutos. A incerteza relacionada aos offsets lineares foi definida por meio da execução do controle dimensional da plataforma de sondagem, em que optou-se por empregar a técnica TEAI (Trilateração Espacial com Ajustamento Inercial), desenvolvida por Ferreira (2019b). Os resultados foram condizentes com o alcançado por Mundy (2017). Por fim, as incertezas associadas aos

\footnotetext{
${ }^{1}$ Refere-se ao erro devido à correção da diferença entre a maré na área do levantamento e aquela observada na estação maregráfica na costa. Aplica-se apenas a levantamentos em áreas oceânicas (IHO, 2005).
} 
movimentos da embarcação foram estimadas considerando uma incerteza na medição do pitch e roll de aproximadamente $0,05^{\circ}$, isto é, um resíduo em roll de $0,05^{\circ}$ conduziria a um erro horizontal de aproximadamente 5 centímetros em uma profundidade de 50 metros (TELEDYNE MARINE, 2019).

Como pode ser observado, existem mais fontes de incertezas verticais do que horizontais. Isso é de fato verdade e pode ser confirmado em HARE (1995), IHO (2005), Ferreira et al. (2016a), dentre outros. Neste estudo, conforme discutido, foi considerado um sistema monofeixe, logo algumas fontes de incertezas presentes nas sondagens multifeixe são desconsideradas e outras precisam de adaptações teóricas (basicamente a suposição de um feixe nadiral).

As incertezas na medição do draft estático e a sua variação durante o levantamento, bem como aquelas introduzidas pelo draft dinâmico foram estimadas com base em experimentos práticos e confirmados, por exemplo, por Calder e Mayer (2003). As incertezas referentes ao ecobatímetro e aos resíduos provenientes das medições do efeito heave foram baseadas nos catálogos dos equipamentos utilizados na pesquisa prática (TELEDYNE MARINE, 2018, 2019).

As incertezas associadas aos movimentos de pitch e roll foram estimadas com base em equações matemáticas propostas por IHO (2005), em que se considerou um feixe sonoro de $6^{\circ}$ (AIRMAR, 2009) e uma incerteza angular do sensor de movimentos de $0,05^{\circ}$ (TELEDYNE MARINE, 2018). Quanto aos resíduos associados a velocidade do som, apesar da disponibilidade do SVP modelo Digibar S, com precisão nominal, ao nível de confiança de $68 \%$, de $0,05 \mathrm{~m} / \mathrm{s}$ (TELEDYNE MARINE, 2009), optou-se por empregar uma incerteza na medição da velocidade do som de $2 \mathrm{~m} / \mathrm{s}$. Com relação às incertezas associadas às variações espacial e temporal, seguiu-se o definido em Linz (2010). Por fim, as incertezas relacionadas aos dados de maré, cálculo do nível de redução e efeitos cotidais (quando aplicável), foram obtidos em Ferreira et al. (2016a) e Mundy (2017).

Deve-se ressaltar que, a depender da largura de feixe, a declividade relevo submerso também pode contribuir com incertezas verticais e horizontais (IHO, 2005). Entretanto, o levantamento de campo empregado para validar as estimativas de incertezas teóricas, foi conduzido sobre fundo regular e, portanto, o declive do relevo submerso não foi considerado como fonte de incerteza nesse estudo.

Para a estimativa das incertezas totais nas componentes vertical e horizontal, isto é, IVT e IHT, aplicou-se o modelo proposto por Ferreira et al. (2016a) em consonância com as teorias de Hare (1995). Assim, todas as fontes de incertezas foram combinadas por meio da lei de propagação de incertezas para calcular as incertezas vertical, horizontal e total da profundidade reduzida para o sistema considerado. Supondo a não correlação entre os contribuintes e uma distribuição aproximadamente normal, as incertezas são dadas pelos conjuntos de Equações a seguir (HARE, 1995; FERREIRA et al., 2016a).

A Equação (1) pode ser empregada para estimar a incerteza horizontal total propagada:

$$
I H T=\sqrt{\sigma_{1}^{2}+\sigma_{2}^{2}+\sigma_{3}^{2}+\sigma_{4}^{2}}
$$

em que:

$\sigma_{1}^{2}:$ Incertezas do sistema de posicionamento;

$\sigma_{2}^{2}$ : Incertezas associadas a sincronização do tempo/latência;

$\sigma_{3}^{2}$ : Incerteza relacionadas às medições e compensações dos offsets lineares;

$\sigma_{4}^{2}$ : Incertezas associadas aos movimentos de roll e pitch da embarcação.

Por meio da Equação (2), pode-se fazer uma estimativa da incerteza vertical total propagada do sistema de sondagem.

$$
I V T=\sqrt{\sigma_{\mathrm{a}}^{2}+\sigma_{b}^{2}+\sigma_{c}^{2}+\sigma_{d}^{2}+\sigma_{e}^{2}+\sigma_{\mathrm{f}}^{2}}
$$

sendo: 
$\sigma_{\mathrm{a}}^{2}$ : Incertezas associadas à medição do draft estático e a sua variação durante o levantamento;

$\sigma_{\mathrm{b}}^{2}$ : Incertezas associadas ao draft dinâmico (Settlement e squat);

$\sigma_{\mathrm{c}}^{2}$ : Incerteza do sonar;

$\sigma_{\mathrm{d}}^{2}$ : Incertezas relacionadas aos movimentos da embarcação;

$\sigma_{\mathrm{e}}^{2}$ : Incertezas relacionados a estimativa da velocidade do som;

$\sigma_{\mathrm{f}}^{2}$ : Incertezas relacionadas à maré e ao estabelecimento do Nível de Redução (Datum Vertical).

Por fim, a IPT no qual se refere, a todas as medidas que contribuem para as incertezas, tanto horizontais quanto verticais, sistemáticas e aleatórias, é calculada pela Equação (3):

$$
I P T=\sqrt{(I V T)^{2}+(I H T)^{2}}
$$

Uma vez que a incerteza variará consideravelmente com a profundidade, uma análise mais completa é realizada por meio de gráficos (incerteza do sistema versus profundidade) (Figura 3). Todas as equações e gráficos foram implementadas em ambiente R (R Core Team, 2020).

Figura 3 -Incertezas teóricas versus profundidades.

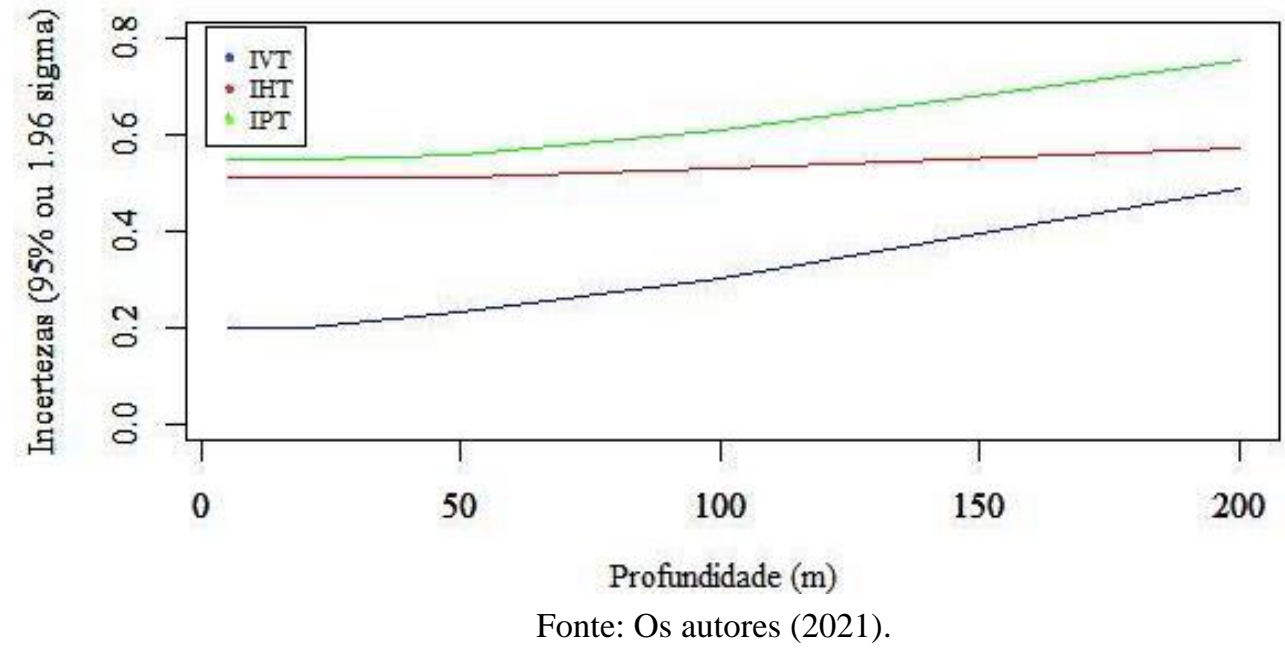

Analisando os resultados (gráficos e tabelas acima), constata-se que a incerteza vertical teórica do sistema de sondagem é cerca de 20 centímetros para profundidades variando entre 5 e 25 metros, enquanto a incerteza horizontal teórica é aproximadamente 0,51 metros. Para maiores profundidades, acima de 50 metros, a IVT chega até 0,50 metros. Nota-se, ainda, que a incerteza horizontal é dependente sobretudo da incerteza posicional da metodologia de posicionamento GNSS empregada, portanto, ao substituir o receptor DGPS (Differential Global Positioning System) por um sistema de posicionamento RTK (Real-time Kinematic), a qualidade horizontal poderá melhorar substancialmente (STATECZY et al., 2020).

No que concerne a IPT, é possível perceber que a sua magnitude é afetada principalmente pela componente IHT. Em todos os casos, ao confrontar estes valores com as tolerâncias de incertezas praticadas pela Diretoria de Hidrografia e Navegação (DHN, 2017) e pela Organização Internacional da Hidrografia (IHO, 2008), verifica-se que o sistema é capaz de alcançar os requisitos de levantamentos hidrográficos mais restritos (Figuras 4 e 5). 
Figura 4 - Comparação dos valores da IVT e as tolerâncias da S-44 (IHO, 2008).

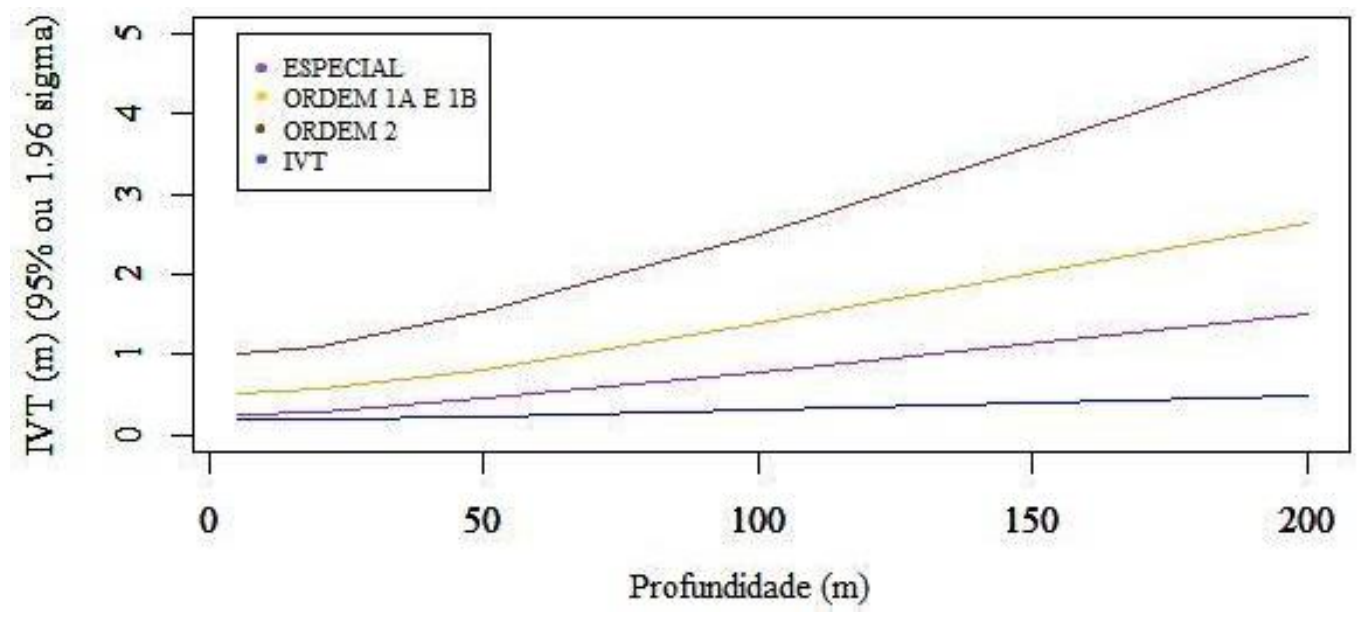

Fonte: Os autores (2021).

Figura 5 - Comparação dos valores da IHT as tolerâncias da norma S-44 (IHO, 2008).

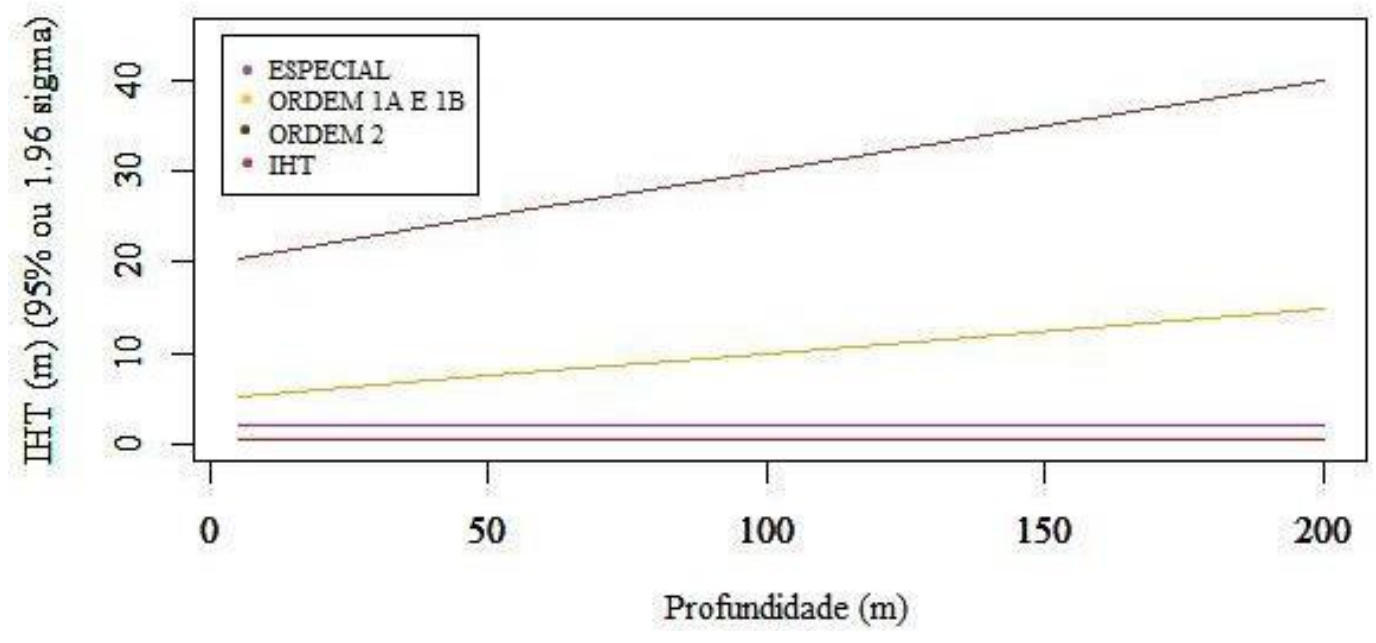

Fonte: Os autores (2021).

Deve-se atentar que os valores aqui apresentados derivam de uma análise teórica. Isto é, o cálculo realizado apenas demonstra a capacidade do sistema de levantamento, não leva em consideração a aleatoriedade de medidas obtidas naturalmente, como é o caso das sondagens. Além disso, conforme afirma a DHN (2014), simplesmente fazer uso de um equipamento teoricamente capaz de fazer face à incerteza requerida, não é necessariamente o bastante.

\subsection{Estimativas das incertezas amostrais}

Visando validar o modelo teórico de incertezas, foi conduzido um experimento prático na Laguna da Jansen, em São Luís, no estado do Maranhão. A Figura 6 ilustra a área de estudo. 
Figura 6 - Área de estudo.

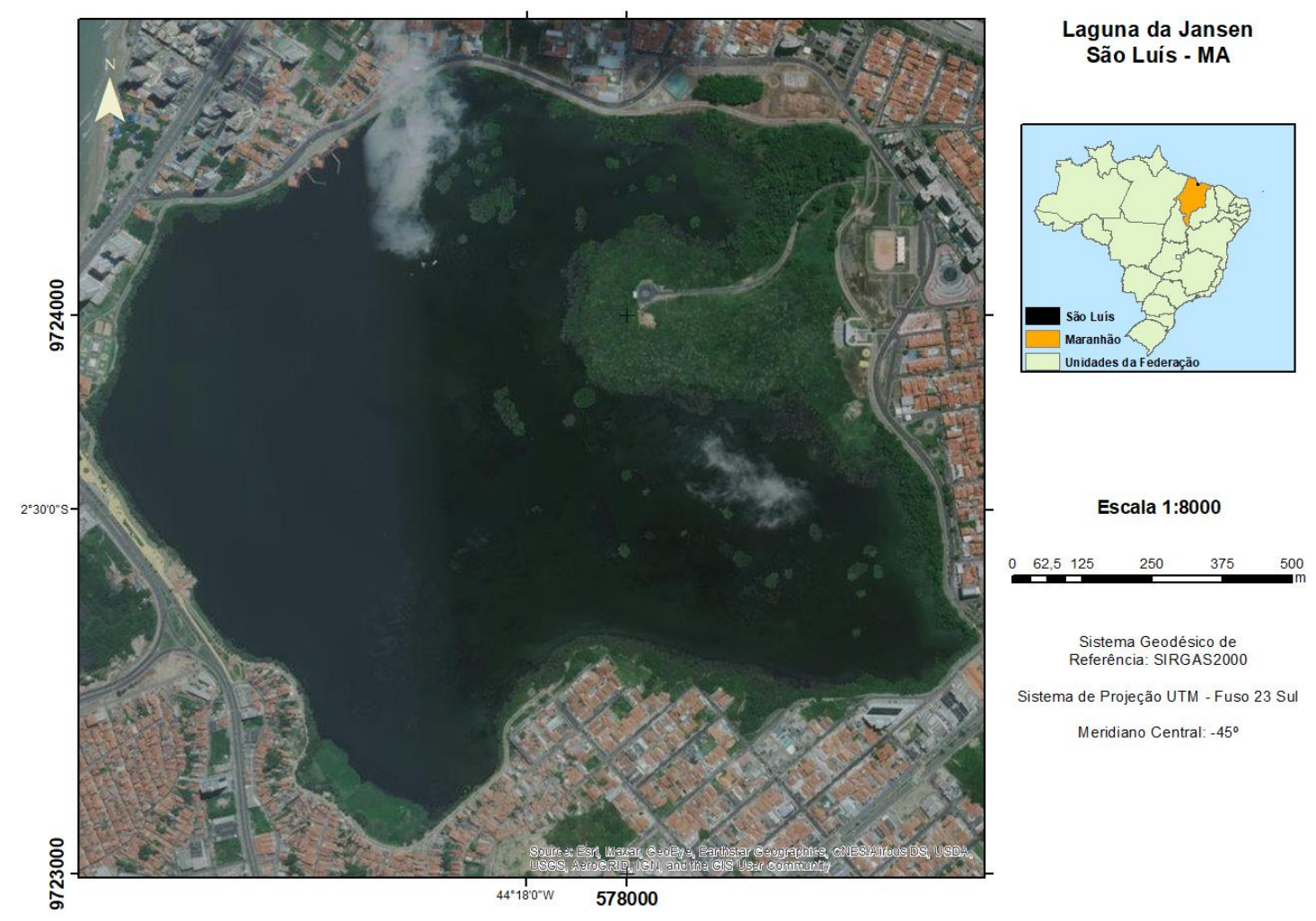

Fonte: Os autores (2021).

O planejamento do LH seguiu as recomendações de Usace (2013), Clarke (2014) e DHN (2017). Foram planejadas 78 linhas regulares de sondagem espaçadas de 25 metros, 10 linhas de verificação com espaçamento de 100 metros, além de 63 linhas internas (inner lines) espaçadas de 20 metros e perpendiculares ao canal existente, permitindo um maior detalhamento da região (Figura 7).

Figura 7 - Planejamento do levantamento batimétrico.

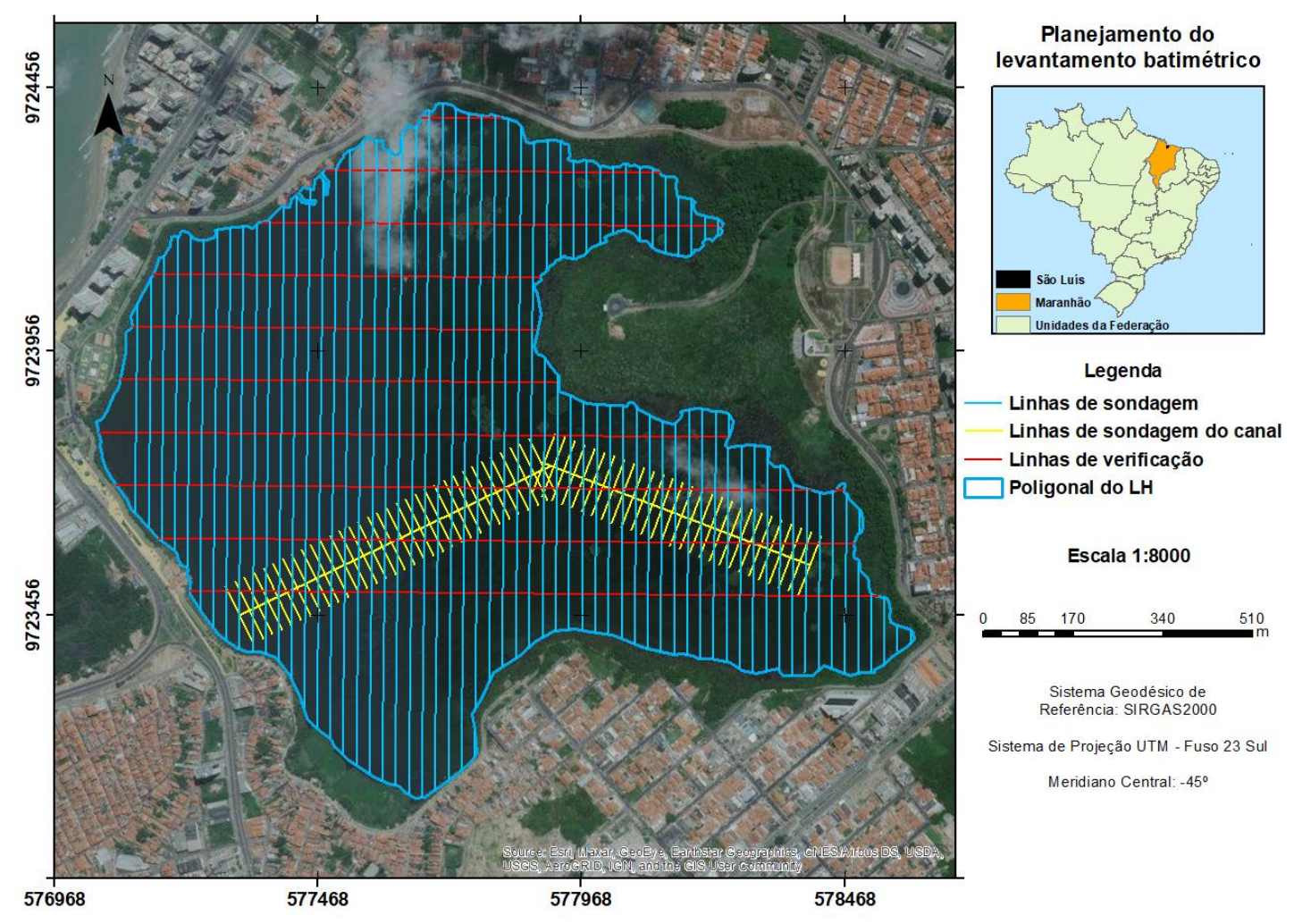

Fonte: Os autores (2021). 
Previamente à execução do $\mathrm{LH}$, procedeu-se com a instalação e nivelamento de uma régua linimétrica às margens sudoeste da Laguna da Jansen, com objetivo de definir o nível de redução das profundidades e efetuar o controle do nível da água durante a sondagem batimétrica. A régua foi nivelada em relação à $\mathrm{RN}$ 2732N pertencente a RAAP (Rede Altimétrica de Alta Precisão) do IBGE (Instituto Brasileiro de Geografia e Estatística).

O datum vertical do LH (nível de redução) foi definido, para este estudo, como sendo o nível médio da Laguna da Jansen calculado com base em uma série de 32 dias de observações do nível da água, resultando numa altitude normal de 2,877 metros. Durante o LH verificou-se que o nível da água variou de 2,896 (início do LH) à 2,814 (fim do LH), sendo necessário então, a partir desta informação, uma redução das profundidades ao datum vertical.

Para verificar a integridade e a incerteza horizontal amostral do sistema de posicionamento utilizado no LH, instalou-se a antena do receptor GNSS do sistema de sondagem batimétrica sob um marco geodésico cujas coordenadas foram estimadas com maior precisão. Por meio da comparação entre uma série de coordenadas registradas pelo receptor no modo cinemático e as coordenadas conhecidas da estação pode-se estimar a incerteza horizontal do posicionamento. Optou-se por utilizar a estatística 2DRMS (Duas Vezes a Raiz Quadrada Média do Desvio na Distância Horizontal), que indica, com um nível de confiança de 95\%, a localização de onde os pontos rastreados estariam inseridos (SEEBER, 2003), resultando num valor de 0,304 metros. A Figura 8 ilustra as discrepâncias posicionais obtidas.

Figura 8 - Discrepâncias posicionais das coordenadas rastreadas.

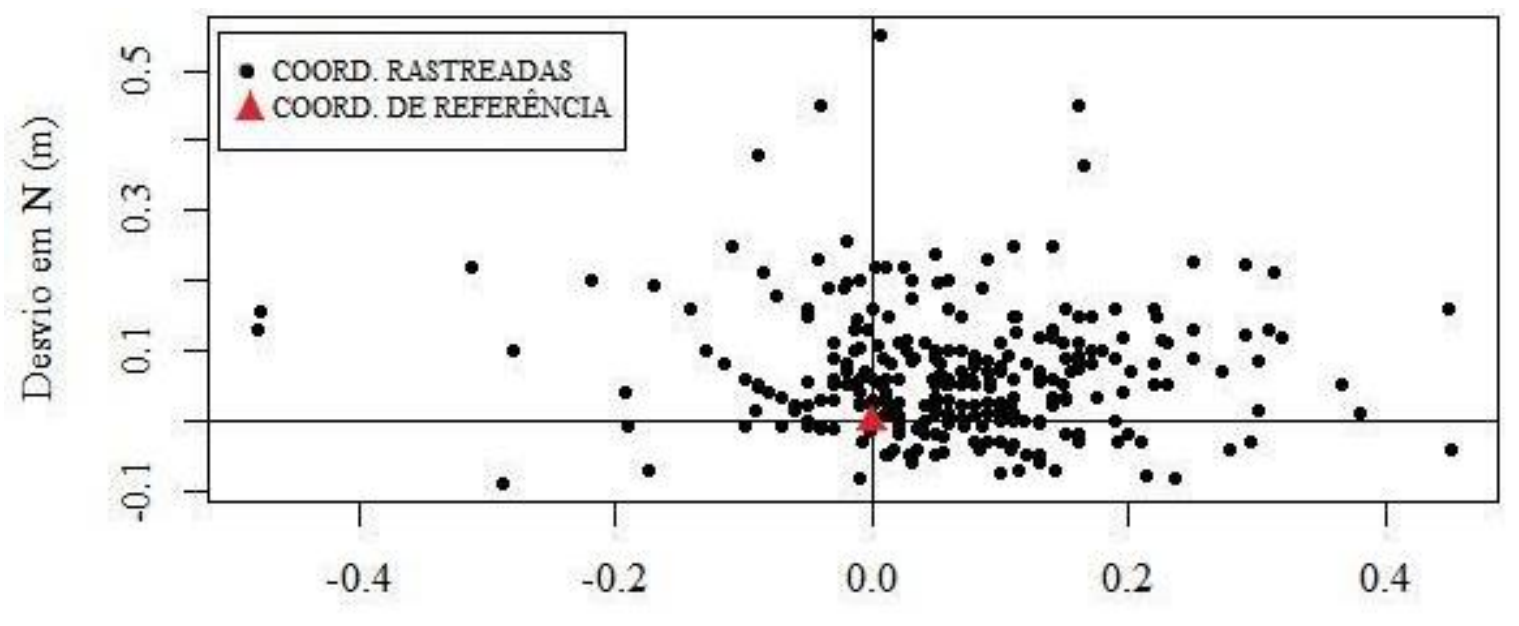

Desvio em E (m)

Fonte: Os autores (2021).

Deve-se atentar que durante a sondagem (posicionamento cinemático) diversas outras fontes de incertezas afetam as coordenadas planimétricas, tais como a atitude da embarcação, resíduos advindos do controle dimensional, latência, etc. Estes não são considerados nesta metodologia de avaliação da incerteza horizontal (FERREIRA et al., 2019a), fato que justifica a diferença entre a IHT (Tabela 1) e a incerteza horizontal amostral (Figura 8).

Todo o levantamento batimétrico foi executado no modo autônomo e durou cerca de 30 horas, entre os dias 10 e 12 de fevereiro de 2020. Ressalta-se que durante a sondagem foram coletados 10 perfis de velocidade do som. Para processamento das profundidades, adotou-se o perfil de velocidade do som geograficamente mais próximo. O processamento dos dados foi executado no software Hypack (HYPACK, 2012), mesmo programa utilizado no planejamento e coleta dos dados. Posteriormente, o arquivo de discrepâncias resultante da confrontação entre as linhas regulares de sondagem e as linhas de verificação foi estatisticamente tratado com objetivo de estimar a incerteza vertical amostral, conforme metodologia proposta por Ferreira (2018) e Ferreira et al. (2019a). 
Inicialmente, as discrepâncias verticais foram submetidas a uma análise exploratória, sumarizados na Tabela 3 e na Figura 9:

Tabela 3 - Análise exploratória das discrepâncias.

\begin{tabular}{l|c}
\hline Observáveis & 337 \\
Média (m) & 0,059 \\
Mínimo (m) & $-0,48$ \\
Máximo (m) & 0,55 \\
Variância (m²) & 0,0155 \\
Desvio Padrão (m) & 0,1247 \\
Coeficiente de curtose & 5,77 \\
Coeficiente de assimetria & $-0,22$ \\
Distância mínima (m) & 0,03 \\
Distância máxima (m) & 1383,214 \\
\hline \multicolumn{2}{c}{ Fonte: Os autores (2021). }
\end{tabular}

Figura 9 - Análise exploratória das discrepâncias.
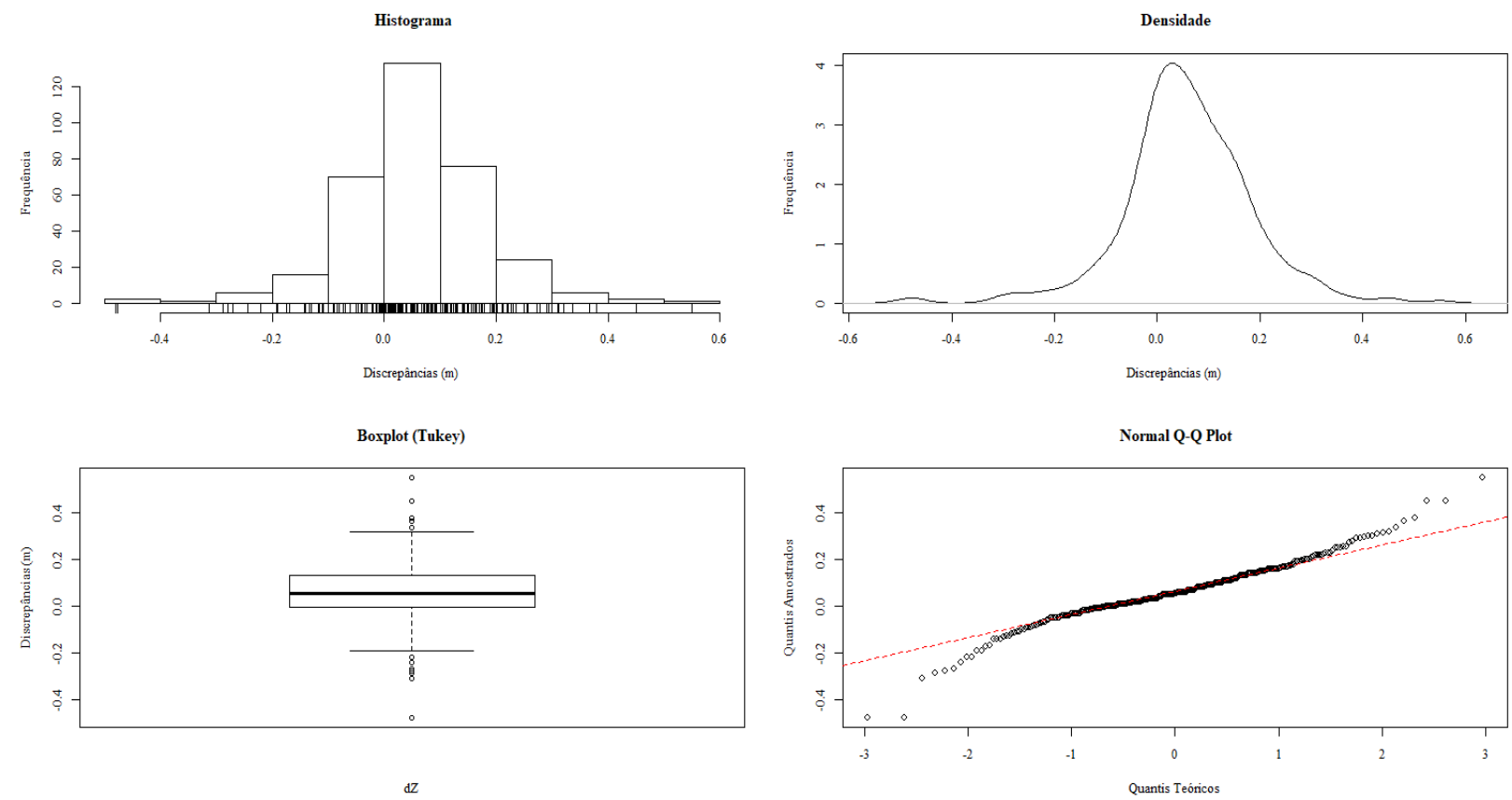

Fonte: Os autores (2021).

Analisando os resultados, percebe-se que a amostra é aproximadamente normal e que possivelmente está contaminada com alguns outliers (Boxplot de Tukey). A primeira suposição não foi rejeitada por meio do teste de normalidade Kolmogorov-Smirnov ( $p$-value: 0,3574681) (DOOB, 1949). A aplicação deste teste foi possível, uma vez confirmada a independência espacial (FERREIRA, 2018) (Figura 10). 
Figura 10 - Semivariograma experimental.
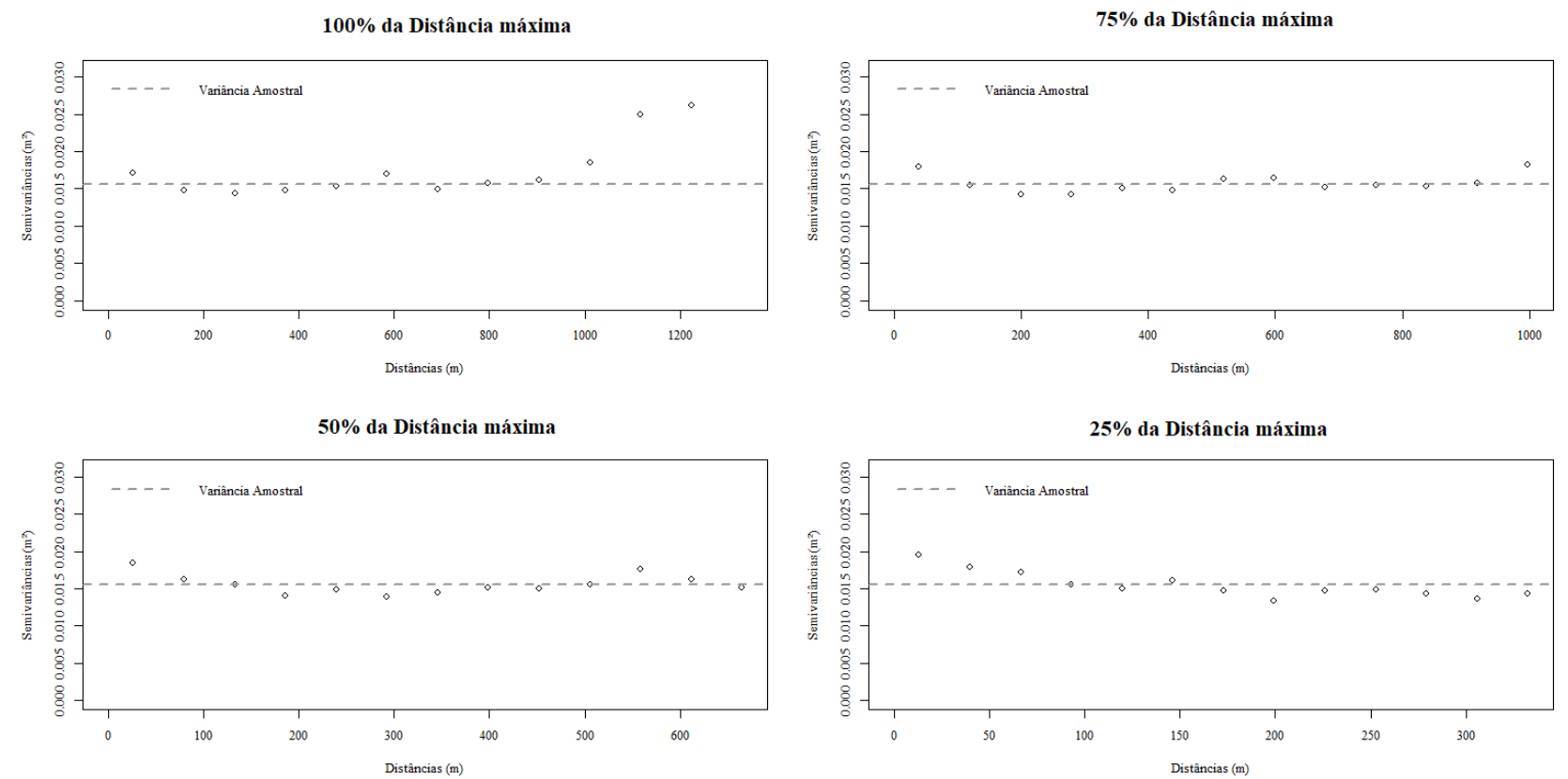

Fonte: Os autores (2021).

Os possíveis outliers também foram analisados empregando o Boxplot ajustado, Z-score modificado (IGLEWICZ;HOAGLIN, 1993) e o método, sendo o último desenvolvido por Ferreira (2018). Contudo, nenhum outlier foi detectado.

Não rejeitada a hipótese de independência e normalidade dos dados, pôde-se estimar a incerteza vertical, ao nível de confiança de 95\%, resultando em 0,138 +- 0,09 metros, conforme estatística proposta por Ferreira et al. (2019a), em que o intervalo de confiança, ao nível de 95\%, foi estimado com base na metodologia Bootstrap. Evidencia-se que todas as profundidades da área de estudo são inferiores a 10 metros, o que resulta numa IVT (incerteza vertical teórica) em torno de 20 centímetros (Tabela 2), isto é, todas as profundidades coletadas com o sistema de sondagem na Laguna da Jansen possuem, teoricamente, uma incerteza vertical de 20 centímetros, ao nível de confiança de $95 \%$.

Confrontando a IVT obtida (Tabela 2) com incerteza vertical amostral, nota-se que o modelo teórico, a priori, subestimou a incerteza dos dados batimétricos, indicando que o sistema não seria capaz de obter profundidades, na área de estudo, com incertezas verticais melhores que 20 centímetros. Porém, ao analisar o arquivo de discrepâncias de um modo geral, observa-se que de fato existem discrepâncias superiores ao valor de incerteza amostral calculada. Na Tabela 3, nota-se que os valores mínimo e máximo de discrepância aproximam-se de 50 centímetros, valor 2,5 vezes superior à IVT. Em complemento aos exames anteriores, sugere-se verificar a distribuição de frequências da amostra de discrepâncias. Neste estudo, em média, $88 \%$ das discrepâncias foram menores que 0,20 centímetros, $95 \%$ foram menores que 0,28 centímetros e $99 \%$ foram inferiores a 0,50 centímetros. O que leva a concluir que apenas $12 \%$ das discrepâncias verticais obtidas em campo foram superiores à IVT. Ressalta-se ainda que, como discutido, a amostra de discrepâncias foi submetida uma análise exploratória e estatística para localizar possíveis outliers.

Por fim, pode-se concluir que o modelo de incertezas foi estimado adequadamente e que, embora a incerteza amostral possa ser estimada por meio de estatísticas, equações matemáticas ou intervalos de confiança, uma análise estatística robusta e detalhada é sempre mais confiável.

\section{CONCLUSÃO}

Neste trabalho foi realizada a avaliação do modelo de incertezas teórico para um sistema de sondagem monofeixe embarcado em um ASV, modelo EchoBoat da empresa SeaFloor Systems. Para isto, foram consideradas as possíveis fontes de incertezas horizontais e verticais, sejam elas sistemáticas ou aleatórias, obtidas em todas as etapas de um levantamento hidrográfico. Estas incertezas foram estimadas com base em 
bibliografias, manuais dos instrumentos e conhecimentos práticos. A metodologia mostrou-se como uma excelente ferramenta de planejamento e pode ser utilizada, por exemplo, para avaliar se determinado sistema de sondagem é capaz de atingir as exigências de incertezas requeridas para uma finalidade específica.

Mesmo assim, pôde-se perceber que os valores teóricos de incertezas (IHT e IVT) não podem ser empregados de forma isolada para a avaliação de um levantamento batimétrico, haja visto que os levantamentos de campo estão sujeitos a incertezas por vezes não modeladas ou subestimadas. Além disso, a lei de propagação de incertezas, nos moldes aplicados, considera que as variáveis são não correlacionadas e seguem uma distribuição normal. Neste contexto, destaca-se que é fundamental que nas atividades de campo empreguem-se equipamentos calibrados, instalados adequadamente e que se tomem os cuidados necessários nas etapas de coleta e processamento.

As incertezas teóricas obtidas (IVT e IHT) foram confrontadas com as incertezas amostrais estimadas com base em um levantamento hidrográfico executado na Laguna da Jansen em São Luís, no estado do Maranhão. Durante o exame estatístico dos dados coletados, constatou-se que o modelo teórico é condizente com as incertezas obtidas em campo. Outra conclusão importante diz respeito a metodologia de estimativa da qualidade vertical do levantamento. Notou-se que a mesma não pode ser representada por um simples numeral ou intervalo de confiança, deve-se estender as análises estatísticas buscando estimativas mais abrangentes.

Como recomendação para complementação deste estudo sugere-se a criação de metodologias para quantificação da incerteza horizontal amostral, assim como a modelagem de incertezas de sistemas multifeixe, formadores de feixe e interferométricos, embarcados em ASV's. Sugere-se ainda, aplicar a metodologia exposta neste trabalho em sistemas LiDAR embarcados em UAV's (Unmanned Aerial Vehicles) e aeronaves tripuladas. Recomenda-se também a realização de uma pesquisa envolvendo um modelo de propagação das incertezas do ASV para parâmetros não-normais ou dependentes, simulando essas incertezas para diversas profundidades.

\section{Agradecimentos}

Os autores agradecem a CODEVASF (Companhia de Desenvolvimento dos Vales do São Francisco e do Parnaíba), ao GEPLH (Grupo de Estudo e Pesquisa em Levantamentos Hidrográficos), ao SIGEOnPA (Soluções em Informações Geoespaciais - Núcleo de Pesquisas Ambientais Avançadas) e ao PIBIC/CNPq (Programa Institucional de Bolsas de Iniciação Científica/Conselho Nacional de Desenvolvimento Científico e Tecnológico - No de Registro dos Projetos: 10764272967 e 10764274441 - pelo apoio e contribuição no desenvolvimento desta pesquisa.

\section{Contribuição dos Autores}

As contribuições dos autores no desenvolvimento deste trabalho são: curadoria dos dados, investigação, metodologia e redação - minuta inicial, supervisão, Italo Oliveira Ferreira; visualização e redação - revisão e edição, Laura Coelho de Andrade; visualização e redação - revisão e edição, Larissa Messias de Souza; visualização e redação - revisão e edição, Arthur Amaral e Silva e visualização, Felipe Catão Mesquita Santos.

\section{Conflitos de Interesse}

Os autores declaram que não há conflito de interesse. 


\section{Referências}

AIRMAR TECHNOLOGY CORPORATION. Guide to Transducer Tecnology - Tranducer TM260, p. 11$12,2009$.

BANDINI, F.; LOPEZ-TAMAYO, A.; MEREDIZ-ALONSO, G.; OLESEN, D.; JAKOBSEN, J.; WANG, S.; BAUER-GOTTWEIN, P. Unmanned aerial vehicle observations of water surface elevation and bathymetry in the cenotes and lagoons of the Yucatan Peninsula, Mexico. Hydrogeology Journal, v. 26, n. 7, p. 2213-2228, 2018.

BYRNES, M.; BAKER, J.; LI, F. Quantifying Potential Measurement Errors and Uncertainties Associated with Bathymetric Change Analysis. USACE - US Army Corps of Engineers.2002.

CALDER, B. R.; MAYER, L. A. Automatic processing of high-rate, high-density multibeam echosounder data. Geochemistry, Geophysics, Geosystems, v. 4, n. 6, 2003.

CHENG, L.; MA, L.; CAI, W.; TONG, L.; LI, M.; DU, P. Integration of Hyperspectral Imagery and Sparse Sonar Data for Shallow Water Bathymetry Mapping. Geoscience and Remote Sensing, IEEE Transactions on, v. 53, n. 6, p. 3235-3249, 2015.

CHURCH, I. W. Multibeam sonar ray-tracing uncertainty evaluation from a hydrodynamic model in a highly stratified estuary. Marine Geodesy, n. just-accepted, p. 1-16, 2020.

CLARKE, J. E. H. Imaging and Mapping II: Submarine Acoustic Imaging Methods. Notes of classes. Ocean Mapping Group. University of New Brunswick, 2014.

CURCIO, J.; LEONARD, J.; PATRIKALAKIS, A. SCOUT-a low cost autonomous surface platform for research in cooperative autonomy.In: Proceedings of OCEANS 2005 MTS/IEEE.IEEE, p. 725-729, 2005.

DIRETORIA DE HIDROGRAFIA E NAVEGAÇÃO (DHN). NORMAM 25: Normas da Autoridade Marítima para Levantamentos Hidrográficos. Marinha do Brasil, Brasil, p.52, 2014.

DIRETORIA DE HIDROGRAFIA E NAVEGAÇÃO (DHN). NORMAM 25: Normas da Autoridade Marítima para Levantamentos Hidrográficos. Marinha do Brasil, Brasil, p. 94, 2017.

DOOB, J. L. Heuristic approach to the Kolmogorov-Smirnov theorems. The Annals of Mathematical Statistics, v. 20, n. 3, p. 393-403, 1949.

EREN, F.; JUNG, J.; PARRISH, C. E.; SARKOZI-FORFINSKI, N.;CALDER, B. R. Total vertical uncertainty (TVU) modeling for topo-bathymetric LIDAR systems. Photogrammetric Engineering \& Remote Sensing, v. 85, n. 8, p. 585-596, 2019.

FERNANDES, V. H.; RODRIGUES, D. D.; AYRES NETO, A.; GUIMARÃES BARBOSA, L. Modeling positional uncertainty for hydrographic surveys with AUV. Journal of Surveying Engineering, v. 145, n. 1, 2018.

FERNÁNDEZ-MONTBLANC, T.; IZQUIERDO, A.; QUINN, R.; BETHENCOURT, M. Waves and wrecks: A computational fluid dynamic study in an underwater archaeological site. Ocean Engineering, v. 163, p. 232-250, 2018.

FERREIRA, I. O. Controle de qualidade em levantamentos hidrográficos. Tese de Doutorado em Informações Espaciais, Programa de Pós-Graduação em Informações Espaciais, Universidade Federal de Viçosa, Viçosa, 2018.

FERREIRA, I. O. EAM410 - Levantamentos Hidrográficos I. Notas de aula. Departamento de Engenharia Civil, setor de Engenharia de Agrimensura e Cartográfica, Universidade Federal de Viçosa, Viçosa, Minas Gerais, 2019c.

FERREIRA, I. O. The Lever Arms measurement: A New approach. In.: 1er KAMPUS Hidrográfico Latino América, 2019, Copacabana, Rio de Janeiro. Kongsberg, $2019 \mathrm{~b}$.

FERREIRA, I. O.; EMILIANO, P. C.; DOS SANTOS, A. DE P.; MEDEIROS, N. DAS G.; DE OLIVEIRA, J. C. Proposição de um Estimador Pontual para Incerteza Vertical de Levantamentos Hidrográficos. 
Revista Brasileira de Cartografia, v. 71, n. 1, p. 1-30, 2019a.

FERREIRA, I. O.; RODRIGUES, D. D.; NETO, A. A.; MONTEIRO, C. S. Modelo de incerteza para sondadores de feixe simples. Revista Brasileira de Cartografia, v. 68, n. 5, p. 863-881, 2016a.

FERREIRA, I. O.; ZANETTI, J.; GRIPP, J. S.; MEDEIROS, N. G. Viabilidade do uso de imagens do sistema Rapideye na determinação da batimetria de águas rasas. Revista Brasileira de Cartografia, v. 68, n. 7, p. 1331-1340, 2016b.

FERREIRA, I. O; NETO, A. A.; MONTEIRO, C. S. O uso de embarcações não tripuladas em levantamentos batimétricos. Revista Brasileira de Cartografia, v. 68, n. 10, 2017.

FURFARO, T. C. A modular guidance, navigation and control system for unmanned surface vehicles. Dissertação (Mestrado). Florida Atlantic University, p. 100, 2012.

GAO, J. Bathymetric mapping by means of remote sensing: methods, accuracy and limitations. Physical Geography, v. 33, n. 1, p. 103-116, 2009.

GIORDANO, F.; MATTEI, G.; PARENTE, C.; PELUSO, F.; SANTAMARIA, R. Integrating Sensors into a Marine Drone for Bathymetric 3D Surveys in Shallow Waters. Sensors, v. 16, n. 1, p. 41, 2015.

HARE, R. Depth and position error budgets for multibeam echosounding. The International Hydrographic Review, v. 72, n. 2, p. 37-69, 1995.

HARE, R.; EAKINS, B.; AMANTE, C. Modelling bathymetric uncertainty. The International Hydrographic Review, n. 6, p. 31-42, 2011.

HEMISPHERE. Global Correction Services for GNSS. Whitepaper, 2018.Disponível em: <https://www.hemispheregnss.com/wpcontent/uploads/2018/12/hemispheregnss_atlas_whitepaper_2018 1119.pdf $\geq$. Acesso em: 01 abr. 2020.

HOY, S.; WHITE, M. P. Mapping Data Acquisition and Processing Summary Report. NOAA - National Oceanic and Atmospheric Administration, 2020.

HYPACK, Inc. Hypack - Hydrographic Survey Software User Manual. Middletown, USA, p. 1784, 2012.

IGLEWICZ, B.; HOAGLIN, D. How to detect and handle outliers. Milwaukee, Wis.: ASQC Quality Press, p. 87, 1993.

INTERNATIONAL HYDROGRAPHIC ORGANIZATION (IHO). Manual on Hydrography. Mônaco: International Hydrographic Bureau, p. 540, 2005.

INTERNATIONAL HYDROGRAPHIC ORGANIZATION (IHO). S-44: IHO Standards for Hydrographic Surveys. Special Publication n. 44 - 5th. Mônaco: International Hydrographic Bureau, p. 36, 2008.

INTERNATIONAL HYDROGRAPHIC ORGANIZATION (IHO). S-44: IHO Standards for Hydrographic Surveys (draft). Special Publication n. 44 - 6th. Mônaco: International Hydrographic Bureau, p. 49, 2020.

JI, D.; LIU, J. Multi-beam sonar application on autonomous underwater robot. Marine Geodesy, v. 38, n. 3, p. 281-288, 2015.

KREITMAIR, M. J. DRAPPER, S.; BORTHWICK, A. G.; VAN DEN BREMER, T. S. The effect of uncertain bottom friction on estimates of tidal current power. Royal Society Open Science, v. 6, n. 1, p. 180941, 2019.

LINZ - Land Information New Zealand. Contract Specifications for Hydrographic Surveys. New Zealand Hydrographic Authority, v. 1, n. 2, p. 111, 2010.

LUCIEER, V.; HUANG, Z.; SIWABESSY, J. Analyzing uncertainty in multibeam bathymetric data and the impact on derived seafloor attributes. Marine Geodesy, v. 39, n. 1, p. 32-52, 2016.

MANLEY, J. E. Unmanned surface vehicles, 15 years of development. In: OCEANS 2008, IEEE, p. 1-4, 2008.

MOUSAZADEH, H.; HAMID, J.; ELHAM, O.; FARSHID, M.; ALI, K.; YOUSEF, S. Z.; ASHKAN, M. Experimental evaluation of a hydrography surface vehicle in four navigation modes. Journal of Ocean Engineering and Science, v. 2, n. 2, p. 127-136, 2017. 
MUNDY, D. Multibeam Survey of Durand Reef, New Caledonia In support of the salvage of MV KEA TRADER. Pacific Comunity. Geoscience Division, 2017.

PEREIRA, D. L. S. Incertezas e controle de qualidade na medição de profundidades por meio de ecobatímetros multifeixe. Anais Hidrográficos - Diretoria de Hidrografia e Navegação, Niterói, Rio de Janeiro, 2016.

R CORE TEAM. A language and environment for statistical computing. Vienna, Austria: R Foundation for Statistical Computing; 2012. URL https://www. R-project. org, 2020.

SEAFLOOR SYSTEM. EchoBoat DataSheet.2017. Disponível em: <https://90bad3e4-1784-40fb-a37b2016d39a0b4d.filesusr.com/ugd/7fd758_9f521ab5885a42c182f34b4c0949f03a.pdf>. Acesso em 05 abr. 2020.

SEEBER, G. Satellite Geodesy, 2nd completely revised and extended edition. Walter de Gruyter GmbH \& Co. KG, v. 10785, p. 303-304, 2003.

SENIOR, H. L. Levantamento Hidroceanográfico para atualização da Carta Náutica 1622-Brasil-Costa Sul-Baía de Sepetiba-Levantamento de Final de Curso-Instrução Especial LH - 021/2012. 2012. Relatório Final. Mangaratiba, Rio de Janeiro.

SPECHT, M.; SPECHT, C. Hydrographic survey planning for the determination of territorial sea baseline on the example of selected Polish sea areas. International Multidisciplinary Scientific GeoConference: SGEM: Surveying Geology \& mining Ecology Management, v. 18, p. 829-836, 2018.

STATECZY, A.; BURDZIAKOWSKI, P.; NAJDECKA, K.; DOMAGALSKA-STATECZNA, B. Accuracy of Trajectory Tracking Based on Nonlinear Guidance Logic for Hydrographic Unmanned Surface Vessels. Sensors, 20(3), 832.2020. DOI: https://doi.org/10.3390/s20030832.

TELEDYNE MARINE. Digibar S - Self Contained Sound Speed Profiler. 2009. Disponível em: <https://seatronics-group.com/files/7614/2185/3786/Teledyne_Odom_Digibar_S_-_Datasheet.pdf $\geq$. Acesso em 02 abr. de 2020.

TELEDYNE MARINE. Echotrac CV100 - Single or Dual Channel Echo Sounder. Product Leaflet. 2018. Disponível <http://www.teledynemarine.com/Lists/Downloads/EchoTrac\%20CV100\%20Product\%20Leaflet.pdf>. Acesso em 3 abr. de 2020.

TELEDYNE MARINE. Specifications of DMS-05 TSS. Product Leaflet, 2019. Disponível em: <http://www.teledynemarine.com/Lists/Downloads/DMS\%20Motion\%20Sensors\%20product\%20leaflet .pdf>. Acesso em 03 abr. de 2020.

USACE - U.S. Army Corps of Engineers. Hydrographic Surveying. Engineer Manual n. 1110-2-1003. Department of the Army. Washington, D. C. USA, 2013.

VANECK, T. W.; RODRIGUEZ-ORTIZ, C. D.; SCHMIDT, M. C.; MANLEY, J. E. Automated bathymetry using an autonomous surface craft. Navigation, v. 43, n. 4, p. 407-419, 1996.

ZHAO, J.; YAN, W.; JIN, X. Brief review of autonomous surface crafts. ICIC Express Letters, v. 5, n. 12, p. 4381-4386, 2011. 


\section{Biografia do autor principal}

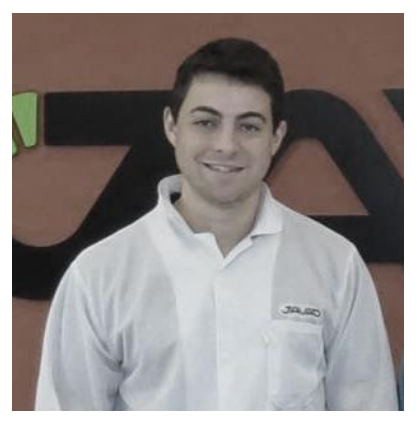

Italo Oliveira Ferreira, nascido em Março de 1988, em Manhuaçu, Minas Gerais, Brasil. Engenheiro Agrimensor e Cartógrafo (2007-2011), com mestrado (20112013) e doutorado (2015-2018) em Informações espaciais (Hidrografia), ambos pela Universidade Federal de Viçosa-UFV. Possui experiência na área de Geociências, com ênfase em Engenharia de Agrimensura e Cartográfica, atuando principalmente nos seguintes temas: Hidrografia, Geodésia, LiDAR, Ajustamento de Observações, Geoestatística e Controle de Qualidade. Atualmente é professor do curso de Engenharia de Agrimensura e Cartográfica da UFV e membro permanente do Programa de Pós Graduação em Engenharia Civil, área de concentração em Informações Espaciais (PGEC/UFV - mestrado e doutorado). 